\title{
An example of using history of mathematics in classes
}

\author{
Sevda Goktepe ${ }^{1}$, Ahmet Sukru Ozdemir² \\ ${ }^{1}$ Department of Elementary Mathematics Education, Yildiz Technical University, Istanbul, Turkey \\ 2 Department of Elementary Mathematics Education, Marmara University, Istanbul, Turkey \\ For correspondence: goktepe@yildiz.edu.tr
}

\begin{abstract}
:
In recent years, the topic of integrating history to mathematics lessons in teaching-learning processes has been frequently discussed among researchers. The main aim of this study is to present an example activity which enriched with history of mathematics and to take the views of students about teaching course in this way. In addition, to create awareness about the developmental stages of mathematics up to now is an implicit purpose. This research is a multiple case study. It was studied with twenty one students who continued eighth grade class in a private primary school. Worksheets containing two algorithms about calculating the square roots of numbers which were used in history were given to each student. In addition, after students reached the solution, they compared their results with results which they obtained from the calculator. Thus, they also saw that the calculator's operating system was similar to algorithms they used. Students' opinions about the integration of the history of mathematics to lessons were collected through an interview form. At the end of the activity, students stated that the chosen activities from the history of mathematics had attracted their interests. Also, they found an opportunity to compare different methods.
\end{abstract}

Keywords: History of mathematics, extracting square root, using calculator.

\section{Introduction}

Mathematics has an important role throughout the history of science (Fauvel, 1991). As a result of its significant role, teaching process should be organized in way that students can develop a positive attitude towards mathematics. Students should believe that mathematics can make their lives easier. Therefore, teaching mathematics must be performed in an environment where students are willing to learn mathematical knowledge and can reach new knowledge on their own. Also, with the help of effective mathematics instruction, students may take mathematical concepts in a more meaningful and interesting way and they may have the opinion that mathematics is not an isolated discipline (Carter, 2006). History of mathematics can be used to achieve these goals.

In fact, the idea of using history of mathematics in mathematics education is not new. History of mathematics has been used in mathematics lessons since 1960s and 1970s (Fried, 2001), but the important role of the history of mathematics in teaching and learning process has increased in the last 20 years (Schubring, Furinghetti \& Siu, 2012; Fauvel \& Maanen, 1997). In 1995, The Institute about the History of Mathematics and Its Use in Teaching (IHMT) was established to support learning mathematics through including historical sections in the teaching and learning processes in mathematics lessons. Then, in 1996, in ICME (The meeting of the International Congress on Mathematics Education) the necessity of some studies to motivate the students and to use the history of mathematics in teaching activities was emphasized (Marshall, 2000). The question about which areas will be more effective while using the history of mathematics in the classroom is an important question. This question was discussed in the panel called "The Role of the History of Mathematics in Mathematics Education", in the ICTM-2 International Teaching Mathematics Conference in 2002.

The National Council of Teachers of Mathematics (NCTM, 2000) indicated that as mathematics is one of the most important disciplines which was created by humans, its development stages should be shown to students in an entertaining way. Moreover, historical improvements from different cultures 
might take part in mathematics curriculum (NCTM, 2003). Sui and Tzanakis (2004) stated that history of mathematics was an integral part of the subject of mathematics.

According to Fried (2001) teachers might give a place to history of mathematics for two purposes in their lessons: To help teaching mathematics and to learn the own history of mathematics. The dynamic structure of mathematics which is arisen from its own nature is actually important in terms of seeing the steps by including history of mathematics.

Liu (2003) presented five reasons why history of mathematics should be included in mathematics lessons. These reasons are; historical knowledge increases students' motivation and helps them to develop a positive attitude towards mathematics, seeing the obstacles experienced in the development of mathematics in the past allows them to see difficulties encountered in present, to solve problems from history helps the development of students' mathematical thinking, history brings out the human side of mathematical knowledge and it is a guide to teachers.

In recent years, studies which express that history of mathematics should be integrated to mathematics lessons have become widespread in the world (Fauvel \& Maanen, 1997; Marshall, 2000; Liu, 2003; Gönülateş, 2004; Carter, 2006; Goodwin, 2007; İdikut, 2007; Albayrak, 2008; Tözlüyurt, 2008; Gürsoy, 2010, Alpaslan, 2011; Swetz, 1994; Fauvel, 1991; Furinghetti, 1997; Van Maanen, 1997; Sui, 2004). In these studies, it was mentioned that there were many benefits to include the history of mathematics in mathematics lessons for both teachers and students. For example, it is an effective tool for motivating students (Fauvel, 1991; Swetz, 1994). Students can learn some of the calculation methods, where some impressions or words come from with the help of these means and can ask questions in this direction (Bidwell, 1993; Kelley, 2000; Rubinstein \& Schwartz, 2000; Tzanakis \& Thomaidis, 2000; Jankvist, 2009; Wilson \& Chauvat, 2000).

Students may have an idea about which important developments related to mathematical topics that are interesting for them have occurred by learning history. They can see that mathematic is a science that people created in accordance with the needs of people. They may be more willing to learn as history of mathematics reveals long traditions, different cultures, people's feelings and developments. Moreover, they can realize why they need to learn mathematics and the source of mathematics. Many studies also support the situation on the results of affecting the students' achievement, interests and attitudes positively by including history of mathematics in lessons (Carter, 2006; Goodwin, 2007; İdikut, 2007; Liu, 2003; Marshall, 2000; Tözlüyurt, 2008).

Marshall (2000) noted that students who had negative attitudes towards mathematics lessons in secondary schools changed positively with the use of history of mathematics. In addition, it was mentioned in the study done by McBride and Rollins (1977) that using history of mathematics affected students' attitudes towards mathematics in a positive way.

Gönülateş (2004) tried to identify ways of using history in her study and to determine pre-service teachers' attitudes towards using history of mathematics. After she carried out lessons with the history of mathematics, she had found that there was not any significant change in pre-service teachers' attitudes. She linked this result with the fact that they had already had a positive attitude.

Gürsoy (2010) found that pre-service teachers had developed a positive attitude about the using of the history of mathematics in teaching-learning process in mathematics lessons. The information supporting this result was obtained through semi-structured interviews.

In the master thesis of Alpaslan (2011), knowledge of elementary mathematics pre-service teachers and their attitudes and beliefs about the use of history of mathematics in mathematics teaching were examined and also whether there was a correlation between these two was also searched. According to the results of analysis, pre-service teachers' scores of knowledge of history of mathematics increased according to their grade levels. In addition to that, teachers' attitudes and beliefs about using the history of mathematics in mathematics education increased, too. 
As expressed in the studies of Marshall (2000), Gönülateş (2004), Gürsoy (2010) and Alpaslan (2011), using history of mathematics in lessons affected students' or pre-service teachers' attitudes positively. While designing the study, these results became motivator force.

The purpose of İdikut's (2007) survey was to investigate the effect of using the history of mathematics as a method for supporting to test the attitudes of students' mathematical performance and their retention levels. In his experimental study, he applied a pre-test and a post-test to 7th grade students. Two groups were chosen from two schools and one of them was determined as control group and the other was determined as an experimental group. Before the study, an attitude scale and a performance test were applied as a pre-test. During four weeks, while mathematics lessons were carried out by adding the history of mathematical techniques in experimental group, teacher used only a text book in control group's lessons. Then, the two scales were applied again. After three weeks, the performance test was conducted again to test the level of retention. Worksheets about mathematicians such as Carl Friedrich Gauss, Leonardo Fibonacci, Omar Khayyam, and Pierre de Fermat were used as teaching materials. It was focused on the impact of especially different cultures to mathematics in worksheets. It was also emphasized the place of mathematics in daily life and in the development of civilizations. Results showed that the course supported by the history of mathematics did not have any effect on the students' attitudes and levels of retention, but there were many effects on the students' achievement in mathematics lessons. Since this study was carried out with elementary school students and by using worksheets, it entered into the literature.

Tözlüyurt (2008) searched whether using history of mathematics had an effect on mathematics teaching and learning. In his study, he sought to answer that question "What are the opinions of last grade high school students' on the lessons carried out with activities chosen from the history of mathematics in learning numbers subject?" Opinions of students on the lesson taught with activities chosen from the history of mathematics collected through interviews. The results were interpreted by examining the phenomenographic method. All eight students participated in the study mentioned that they thought mathematics in fact as a difficult lesson, but they found the lesson interesting, more funny and easy when it was taught in this way. They stated that they could easily understand problems and theorems and could easily make inferences with by using the history of mathematics and they could understand and could also make inferences easily. They also noted that they were provided to see the phases of mathematics until today. As students' opinions were taken in his study so it is thought that it is related with this study.

Albayrak (2008) used the history of mathematics in teaching the volume of pyramids, cones and spheres. The effects of this practice on the perception of mathematics self-efficacy and success were tested. Quantitative and qualitative data was collected in the study and it was concluded that there was a significant difference between pre-test and post-test in terms of the experimental and control group students' achievements in mathematics in both schools. However, according to the results, students from experimental group were more successful than students in the control group only in one of the participated school. According to the qualitative data, generally the experimental group students had positive thoughts about the lesson carried out by using the history of mathematics.

Goodwin (2007) made a qualitative study to explore the correlation between high school mathematics teachers' knowledge about history of mathematics and their opinions on the mathematics. "Mathematical images research" and "History of Mathematics Test" sent to 900 high school teachers, the data was obtained from 193 of them and a significant correlation was found between knowledge about history of mathematics teachers and opinions in the mathematics. In addition to that teachers who were more successful in history lessons were also successful in mathematics lessons. As this study had a qualitative part, Goodwin's (2007) and Albayrak's (2008) studies entered into the literature.

According to the study of Karakuş (2009), including history of mathematics in lessons helped students to see the changing and evolving nature of mathematics. In his paper, he prepared an example of worksheet about taking square roots of numbers. The traditional method of taking square roots is different from the method which was stated in the worksheet prepared during this study. In 
addition to that, he expressed that examining the studies of famous mathematicians might be useful for developing different solutions to problem solving.

If the place of the history of mathematics is examined in elementary school mathematics curriculum in Turkey, it will be understood that the history of mathematics is used in different grade levels. There is brief information on the history of money for $6^{\text {th }}$ grade students and the history of rational numbers in learning numbers subject for $7^{\text {th }}$ grade students. In the learning probability subject, the history of probability for $7^{\text {th }}$ grade students and history of the square roots symbol for $7^{\text {th }}$ grade students are mentioned. In the learning measuring subjects, the history of measuring is taught in $6^{\text {th }}$ grades and the history of the pyramids' and volume is taught in $8^{\text {th }}$ grades. In the learning of algebra, a Fibonacci problem about chicks of rabbits for $6^{\text {th }}$ grade students is given. In the learning of geometry, the teaching activity with tangrams is used for $6^{\text {th }}$ grade students, history of pi number for $7^{\text {th }}$ grade students and student projects related to geometry for $8^{\text {th }}$ grade students. Besides, the contributions of Ataturk, Pythagoras, and Escher to mathematics are also mentioned. There is also some information about counting systems of the Mayans and the historical development about fractions in ancient Egypt (Minister of National Education, 2009).

Sub learning field of square root numbers are located in learning of numbers in elementary school mathematics curriculum. Among the objectives of the lesson, there is an expression like this: "She/he estimates the square root of not perfect square numbers by using a strategy." Several ways can be viewed for this objective and there is an example in mathematics curriculum. In the part of remarks, a statement is given like this: " $\sqrt{ }$ " button is introduced from calculator." These statements show that this study corresponds to suggestions of the curriculum. In our study a worksheet which is related to square roots of numbers was created. Thus, it is thought that this study is important in terms of using history in teaching square roots of numbers. Two separate algorithms used by the Babylonians to calculate the square roots of numbers were given. Also, one of the questions in worksheet required the comparison of these two methods. And then, they compared the results found by calculating the square root of the value. The majority of students' answers were close to the values which were verified with a calculator (Minister of National Education, 2009).

In the light of this information, the main purpose of this study is to present an activity that incorporates with the history of mathematics in teaching of the square root algorithm, to show what students think about this kind of activity and whether they acquire something from comparing two ancient algorithms with one another and verifications with a calculator. It is aimed to help them to see the stages of mathematics until the present day, to provide students a different perspective, to show that mathematics is still continuing its development and to show them that mathematics is a living science. Using these methods stated in this activity at other times is not expected, but they can leave a mark in their minds as an alternative way and they can use them in required cases for controlling their results. Besides, it is aimed to bring technology in lessons in basic levels with the use of calculators. Mathematics and history are different disciplines but this study has become important as interdisciplinary association was conducted.

\section{Methodology}

Multiple case study procedure was used for gathering and analyzing information. This methodology defined by Yin in 2009 and he stated that multiple cases resembled in multiple experiments. Generally case studies are descriptive or explanatory. Explanatory case studies try to explain underlying reasons about the situation (Yin, 2009). Besides, according to Thomas (2011) case studies may use one or more procedures to analyze people, circumstances, durations etc. completely. In this study, as seventh grade students' opinions about using history of mathematics in teaching-learning process was examined, multiple case study was preferred. Thus, students' opinions were examined deeply. The working group was composed of twenty one eighth grade students from a private school in 20102011 academic years. 
Process of the Study

The flow chart summarizing the process of the study is as in the following:

1. Creation of worksheets on how to extract square roots of numbers

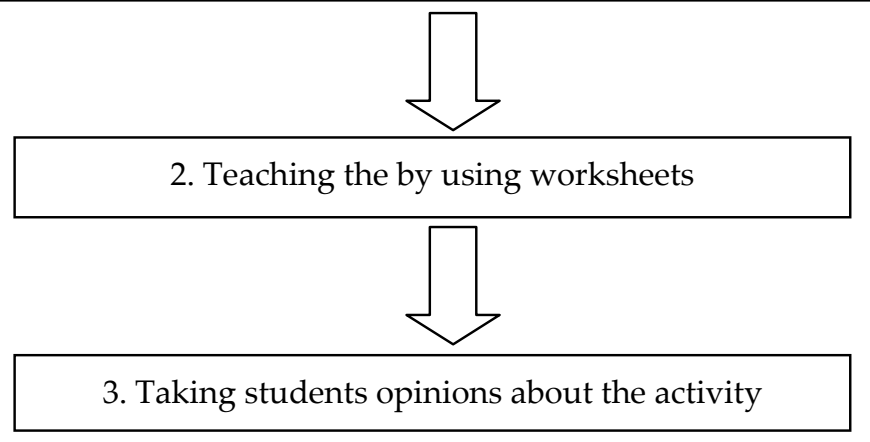

Figure 1. Process of the study

Firstly, a worksheet which students could learn different information about extracting square roots of numbers was created. This worksheet contained two different methods used by the ancient Babylonians to find the square root of numbers.

Creation of the worksheet:

During the creation of the worksheet, basically the book of Swetz (1994) which is called as "Learning activities from the History of Mathematics" was used. Worksheet was related to calculation square roots of numbers by using different ways and two algorithms found by the ancient Babylonian were used in it. Two different algorithms were given to calculate square roots of numbers in the worksheet. The worksheet created was given below:

There was a short explanation on top of the paper to attract students' attention. After this information a question was directed to them.

"Ancient Babylonians knew how to calculate square roots of numbers in a correct way. How could they do it?"

Firstly, brief information about the method used by ancient Babylon was given. After giving the first algorithm in a box, extraction of $\sqrt{7}$ was shown step by step.

\section{To find the value of $\sqrt{n}$}

a. Let's take any number $g_{1}$ smaller than $n$.

b. Let's find $\frac{n}{g_{1}}=a_{1}$ and $\frac{a_{1}+g_{1}}{2}=g_{2}$

c. Let's repeat this process $\frac{n}{g_{2}}=a_{2}$ and $\frac{a_{2}+g_{2}}{2}=g_{3}$

These iterative processes continue till the required accuracy is found.

Let's $g_{1}$ is 2 .

Let's find the value of $\sqrt{7}$

$7 /(2)=3.5, \quad(3.5+2) /(2)=5.5 / 2=2.75=\mathrm{g}_{2}$

$7 / 2.75=2.5454, \quad(2.75+2.5454) /(2)=2.647=\mathrm{g}_{3}$

$7 / 2.647=2.6445, \quad(2.647+2.6445) /(2)=2.6457=\mathrm{g}_{4}$

$7 / 2.6457=2.6458, \quad(2.6457+2.6458) /(2)=2.64575$ 
For verifying the value of $\sqrt{ } 7$, a calculator was used and the number of 2, 64575 was obtained. Also, it was expressed that as the number of attempts were increased; the value of square roots of numbers got closer to the correct value.

After these explanations, the values of $\sqrt{12}$ and $\sqrt{87}$ were asked to calculate. Then, calculations of the square roots of these numbers with a calculator were requested. It was asked to form tables by comparing the results.

Secondly, it was mentioned about another algorithm used by the Babylonian. Apparently; this algorithm is shorter than the first algorithm. Second algorithm is as the following:

$$
\sqrt{a^{2}+h}=a+\frac{h}{2 a}
$$

Similarly, the value of $\sqrt{ } 7$ was calculated as an example by using this algorithm.

Example: By means of this algorithm the value of $\sqrt{7}$ was found as stated below:

$$
\sqrt{7}=\sqrt{2^{2}+3}=2+\frac{3}{4}=2.75
$$

Students were asked to calculate the values of $\sqrt{12}$ and $\sqrt{87}$. The results were compared using a calculator again. It was asked to form tables by comparing the results.

Finally, there was an open-ended question in the worksheet: "Which algorithm is better? Did you explain your answer?"

Processing of the lesson with the worksheet:

Worksheets including two different algorithms used in the history about taking the square root were given to each student. The activity was carried out in one lesson. Students used their calculators at the end of the activity to compare the answers obtained with the help of algorithms in the worksheets with right answers.

Taking students' opinions about the course:

Students' opinions about the integration of the history of mathematics into lesson were collected through an interview form after a lesson which was carried out with the worksheet. Interview form was given to each student and their opinions were taken in a written form.

\section{Data Collection Instruments}

In this section the interview form prepared by researchers are introduced.

\section{The Interview Form:}

It was created for taking the opinions of students about teaching the subject with an activity from history of mathematics. It consisted of seven open-ended questions. Experts' opinions were taken in while designing the form. The interview form was conducted after the activity with worksheet was practiced. 40 minutes was given for completing the form.

The first question was: "Have ever carried out a study like this before?" In the second question, they were asked about whether they liked this activity or not and what they thought about the usefulness of this activity. In the third question, they were asked about in which parts they had difficulty and in the fourth question, they were asked about whether they wanted to do such activities or not. The fifth question was: "What are the benefits of this activity for you?" the sixth question was: "How do you 
associate the subject in the activity with daily life?". Finally, it was aimed to benefit from opinions of the students by asking their suggestions and if they want to add anything in the seventh question.

\section{Data Analysis}

Descriptive analysis was used to analyze student's opinions about teaching mathematics lesson by using activities from history of mathematics. According to Mann (1995) descriptive analysis was used for explaining basic features of data which was collected quantitatively. Yıldırım states that in descriptive analysis collected data is explained and interpreted. Direct quotations are used frequently (as cited in Kurt, 2011).

Significant themes were created from students' opinions by two experts. These themes stated in findings section and interpreted in conclusion part. Quantitative and qualitative methods were used together during data analysis. While responses of first, second and forth questions were given in percent-frequency tables, for other questions determined themes were used. This part is quantitative analysis part. Besides, direct quotations from students' opinions established the qualitative analysis part of the research.

\section{Findings}

The frequency table of students' responses provided for the first question is given below.

Table 1. Opinions of students about whether they have carried out a study like this before or not

\begin{tabular}{cll}
\hline Have you ever carried out a study like this before? & f & $\%$ \\
\hline Yes & 19 & 91 \\
No & 2 & 9 \\
\hline
\end{tabular}

$91 \%$ of students stated that in their mathematics course, they carried out an activity from history of mathematics.

As for the second question, students' opinions were taken about whether they liked the activity or not.

Table 2. Opinions of students about whether they liked this activity

\begin{tabular}{clc}
\hline Did you enjoy from this activity, do you think it is a useful activity? & f & $\%$ \\
\hline Yes & 18 & 86 \\
No & 3 & 14 \\
\hline
\end{tabular}

The majority of students expressed that it was a useful activity. In this context, the following answers were given:

"I liked it; it is so funny like brain training"

"Yes, I had so much fun with my friends"

"Yes, to learn about a variety of methods in mathematics is very nice"

"I did not like it because I did not understand a lot."

When students were asked about the parts that they had difficulty during the activity in the third question, they stated calculation, following the operation steps, understanding algorithms and operating themes. 
Table 3. Parts of students had difficulty

\begin{tabular}{lc}
\hline Themes & $\%$ \\
\hline Calculating & 75 \\
Following the operation steps & 75 \\
Understanding algorithms & 50 \\
Operating themes & 40 \\
\hline
\end{tabular}

Some of the students' answers are as in the following:

"I couldn't do it in time."

"In general, all of them"

"To understand"

"Operations"

"Long-tasking divisions in decimal numbers"

In the fourth question, when they were asked whether they wanted to do such activities, the following results were obtained.

Table 4. Opinions of students about whether they wanted to do such activity

\begin{tabular}{cll}
\hline Do you want to do such activities in the lessons? & f & $\%$ \\
\hline Yes & 27 & 82 \\
No & 6 & 18 \\
\hline
\end{tabular}

The following answers were given as an explanation:

"If it isn't difficult, yes"

"Yes, it is enjoyable"

"Yes, I'm having fun while doing it"

Students were asked what they learned from this activity in the fifth question. Reinforcing the topic, developing mathematics knowledge, learning unknown things, obtaining knowledge from history, comparison ability, using calculator themes were the answers.

Table 5. What they learnt from this activity

\begin{tabular}{ll}
\hline \multicolumn{1}{c}{ Themes } & $\%$ \\
\hline Reinforcing the topic & 80 \\
Developing mathematics knowledge & 75 \\
Learning unknown things & 60 \\
Obtaining knowledge from history & 60 \\
Comparison ability & 40 \\
Using calculator & 30 \\
\hline
\end{tabular}

Also, following responses were given as an example:

"I remembered old subjects"

"Research ability"

"I developed my knowledge of mathematics."

"We developed our brains"

"It helped me to learn things I didn't know."

"I learned some things and I refreshed my information." 
Themes which was stated for the sixth question about how they related this activity with daily life as in the following:

Table 6. Students' opinions about how they related this activity with daily life.

\begin{tabular}{cc}
\hline Themes & $\%$ \\
\hline Relating with history lesson & 30 \\
Learning past & 20 \\
Exploring mathematics & 15 \\
\hline
\end{tabular}

The following answers are provided to the question about how they related this activity with daily life:

"Calculations"

"Major discoveries were made in the past, but they didn't continue."

"I can't associate with daily life"

"I can associate with the history lesson"

"We can recognize the past"

"We learned the past"

In the seventh question students were asked about if they wanted to add something and suggestions. Themes which were stated by students are as in the following:

Table 7. Students' suggestions about this activity

\begin{tabular}{cc}
\hline Themes & $\%$ \\
\hline It should remain without any change & 60 \\
It should be more difficult & 30 \\
It should be more exciting & 30 \\
More time should be allocated & 10 \\
\hline
\end{tabular}

Also, the following answers are collected:

"Everything was very nice; I think it should remain as original."

"I would be glad if challenging questions takes part."

"You can make it funnier."

"No need to add anything, it is really a funny activity"

"Longer time should be given."

\section{Conclusions and Suggestions}

When students were asked whether they had carried out such an activity before or not, $91 \%$ of them answered "yes". This result shows that the worksheets were used as a material in lessons before. The fact that this study was carried out in a private school was effective in obtaining this outcome. In fact, it can be said that alternative methods are more frequently used within the lessons in private schools.

According to the findings of the second question, the majority of students $(86 \%)$ think this activity is useful and they liked it. As a result of using the same methods constantly, students got bored and the use of different method provides them to increase their interests to lessons. In fact, in the fourth question, when the students were asked whether they wish to do like such activities in lessons, 82 percent of them stated that they want to. They already said in the first question that they did such activities before; answers to this question are proving that they are satisfied with this situation.

By giving activities from history of mathematics in lessons, it is easier to get students' attention. They see the development of mathematics from that time. By analysing with today's perspective, they think 
about on the mathematical concepts. Such studies including history of mathematics increase the students' different ideas and ability of understanding theories. By drawing attention to the handmade activities, it increases motivation in mathematics. The lessons including history of mathematics make the lessons more meaningful by increasing the motivation. Thus, the answers to the first and the second questions show that the students' opinions are also in this respect and carrying out lessons like this would be useful. The studies supporting these results in the literature are (Carter, 2006; Marshall, 2000; Alpaslan, 2011; Gürsoy, 2010).

When students were asked in the third question about which sections they had difficulties in the activity, themes created with their answers are as in the following; calculating, to follow the process steps, to understand algorithms, to operate. Students had difficulty mostly in calculation and following the process steps. Particularly, since first algorithm in worksheet consisted of the following steps, it became challenging. The reason why this finding was obtained may not be using such an algorithm before. Students often prefer to use a calculator even for the simplest operations. Even if they have not got a calculator with them, they can reach a solution by using telephones and computers without burdening themselves. To put it clearly, doing a lot of operations in succession may enforce them. Besides, even the students did not express for the first algorithm, continuing operations by anticipating a number for beginning needs to be done at this step is important and it is the main reason for not reaching the right conclusion.

When students were asked about the benefits of the activity in the fifth question, themes created with their answers are as in the following : reinforcing the topic, developing mathematical knowledge, learning new knowledge, obtaining information from history, the ability of comparing, using a calculator. Students mostly arrayed their acquisitions respectively; developing their mathematical knowledge, an opportunity of reinforcing the topic. Opinions on the change of making comparison by using the calculator are not too many. In general, to sum up, the students in this study had the opportunity to work with two different methods to extract square roots. The use of the calculator as a material provided enrichment of the learning environment.

The themes identified for the sixth question about how they associate the activity with daily life are as in the following: association with the history lesson, learning history, discovery of mathematics. From the answers given to this question in general, it can be seen as the students could not associate with daily life. They stated that they obtained information mostly from history. The answers given are similar types. The most important reason in achieving this outcome is not being able to give many examples from daily life in teaching mathematic lessons. Therefore, students could not associate the activity with daily life. Concrete examples should be given about which areas they can be used and how to teach information and some tasks should be given to run their minds in this direction. These tasks can be project assignments. Studies state that projects should be included in mathematic lessons.

In the seventh question, students asked what they want to add and their suggestions. According to the answers received from the students, identified themes are as in the following: It should remain without a change, it must be harder, it must be funnier, and more time should be given. $75 \%$ of the students indicated that the activity was appropriate as this situation and should remain the same. So the majority was satisfied with the activity, but some of them stated an idea that it should be funnier. At this stage, the following recommendations can be given: Each step should be considered in detail while preparing learning activities and the most suitable material should be prepared by estimating the part where the students may have difficulties. Swetz (1994) suggests the following to writers who are preparing a material: Being creative and including appropriate visuals. These visuals may be pictures, articles, or may be a material that can be taken to the classroom environment. He states that in terms of History Learning Tasks (HLT) students should learn not only something about mathematics but also something about how mathematics is done. Allocating the time is really important and in general, students had difficulties in arranging the time. It can be said that some students emphasize on the situation due to the operations took lots of time.

In accordance with these results, other recommendations can be given to as follows: 
In mathematics problems which are solved in terms of iterative process have a great importance. The divide- and- average method for taking square roots of numbers may be used for an example for it. Without giving any algorithm and a calculator, students may be asked to find the results of the square roots of the numbers.

When student were asked to compare the two methods in the worksheet and the determination of the result which was close to the requested value in the calculator were asking the skill of comparing. In question, which method would be better to use is asked. To determine which method can reach to the result in the shortest way and at the shortest time is required in response. To put it more, if time is important, the second method can reach the conclusion more quickly, whereas if reaching the nearest right value is important, first algorithm should be preferred.

Van Maanen (1997) emphasizes the subject that history of mathematics should be take part in lessons. The role of teachers is important. For upbringing experienced and knowledgeable teachers in preparing and selecting the appropriate material, the undergraduate and graduate level education should continue. Information about how to use history of mathematics in the lessons may be included to this education.

Problems from the history of mathematics may be included as different methods in teaching and learning environments. For example, Yedkimov (2006) said that history of mathematics could be used in the method of the invention.

Activities from history of mathematics can be useful for developing students' positive attitudes towards mathematics. Through the exchange of ideas with each other by group working, a social environment in the classroom has formed. In recent years, students are asked to prepare projects in schools.

\section{References}

Albayrak, Ö. (2008). Effects of history of mathematics integrated instruction on mathematics self-efficacy and achievement. Unpublished master's thesis, Boğaziçi University, Institute of Pure and Applied Sciences, İstanbul.

Alpaslan, M. (2011). Prospective Elementary Mathematics Teachers' Knowledge of History of Mathematics and their Attitudes and Belifs towards the Use of History of Mathematics in Mathematics Education. Unpublished master's thesis, ODTÜ, Ankara.

Bidwell, J. K. (1993). Humanize Your Classroom with The History of Mathematics. Mathematics Teacher, 86, 461-464

Carter, D. B. (2006). The Role of the History of Mathematics in Middle School. Unpublished master's thesis, East Tennessee State University, United States.

Fauvel, J. (1991). Using History in Mathematics Education. For the Learning of Mathematics, 11(2), 3-6.

Fauvel, J., Maanen, J. V. (1997). The Role of the history of mathematics in the teaching and learning of mathematics discussion document for an ICMI study (1997-2000). ZDM, 29 (4), 138-140.

Fried, M. N. (2001). Can mathematics education and history of mathematics coexist? Science and Education, 10, 391-408.

Furinghetti, F. (1997). History of Mathematics, Mathematics Education, School Practise: Case Studies Linking Different Domains. For the Learning of Mathematics, 17(1), 55-61

Furinghetti, F. (2000). The history of mathematics as a coupling link between secondary and university teaching. International Journal of Mathematical Education in Science and Technology, 31(1), 43-51.

Gönülateş, F. O. (2004). Prospective teachers' views on the integration of history of mathematics in mathematics courses. Unpublished master's thesis, Boğaziçi University, Institute of Science, Istanbul.

Goodwin, D. M. (2007). Exploring the Relationship Between High School Teachers' Mathematics History Knowledge and their Images of Mathematic. Unpublished doctoral dissertation, University of Massachusetts, Lowell.

Gürsoy, K. (2010). A survey of prospective mathematics teachers' beliefs and attitudes towards using the history of mathematics in mathematics teaching. Unpublished master's thesis, Karadeniz Tecnical University, Institute of Pure and Applied Sciences, Trabzon.

İdikut, N. (2007). Matematik Öğretiminde Tarihten Yararlanmanın Öğrencilerin Matematiğe Yönelik Tutumlarına ve Matematik Başarılarına Etkisi. Unpublished master's thesis, Yüzüncü Yıl University, Van.

Jankvist, U. T. (2009). A categorization of the 'whys' and 'hows' of using history in mathematics education. Educational Studies in Mathematics 71(3), 235-261.

Karakuş, F. (2009). Matematik Tarihinin Matematik Öğretiminde Kullanılması: Karekök Hesaplamada Babil Metodu. Necatibey Eğitim Fakültesi Elektronik Fen ve Matematik Eğitimi Dergisi (EFMED), 3(1), 195-206.

Kelley, L. (2000). A mathematical history tour. Mathematics Teacher, 93(1), 14 - 17.

Kurt, A. A. (2011). Bilimsel Araştırma Yöntemleri, Eskişehir: Anadolu Üniversitesi yayınları.

Liu, P. (2003). Do Teachers Need to Incorporate the History of Mathematics in their Teaching? The Mathematics Teacher, 96(6), 416.

Mann, P. S. (1995) Introductory Statistics, 2nd Edition, Wiley. 
Marshall, G. L. (2000). Using History of Mathematics to Improve Secondary Students' Attitudes Towards Mathematics. Unpublished doctoral dissertation, Illinois State University,United States.

Marshall, G. L., \& Rich, B. S. (2000). The Role of History in a Mathematics Class. Mathematics Teacher, 93(8), 704-706.

McBride, C.C., \& Rollins, J.H. (1977). The Effects of History of Mathematics on Attitudes toward Mathematics of College Algebra Students. Journal for Research in Mathematics Education, 8 (1), 57-61.

Ministry of National Education [MoNE]. (2009). İlköğretim matematik dersi öğretim programı 6-8. sinıflar: Öğretim programı ve kilavuzu. Ankara, Turkey: MoNE

National Council of Teachers of Mathematics (2000). Principles and standards for school mathematics. Reston, VA: Author.

NCATE/NCTM (2003). Standards for Programs for Initial Preparation of Mathematics Teachers, http:/ /www.ncate.org, (accessed Nowember, 2011)

Rubinstein, R. N. \& Schwartz, R. K. (2000). Word histories: Melding mathematics and meanings. Mathematics Teacher, $93(8), 664$ -669 .

Jon, S. \& Greene, R.W. (2003). Sociology and You. Ohio: Glencoe McGraw-Hill.

Siu, M. K. \& Tzanakis, C. (2004). History of mathematics in classroom teaching - appetizer? Main course? Or dessert? Mediterranean Journal for Research in Mathematics Education, 3, 1-2.

Schubring, G., Furinghetti, F. \& Siu, M.K. (2012). Introduction: the history of mathematics teaching. Indicators for modernization processes in societies. $44(4), 457-459$.

Swetz, F. (1994). Learning Activities from the History of Mathematics. The United States of America:J.Weston Walch, Publisher.

Swetz, F. (1995). Some not so random thoughts about the history of mathematics - its teaching, learning, and textbooks. Primus, $5(2), 97-107$.

Thomas, G. (2011). A typology for the case study in social science following a review of definition, discourse and structure. Qualitative Inquiry, 17(6), 511-521

Tözlüyurt, E. (2008). The perceptions of senior high students regarding the course, in which activities chosen from history of mathematics are used on the subject of numbers learning area. Unpublished master's thesis, Gazi University, Institute of Education al Sciences ,Ankara

Tzanakis, C. \& Thomaidis, Y. (2000). Integrating the close historical development of mathematics and physics in mathematics education: Some methodological and epistemological remarks. For the Learning of Mathematics, 20(1), $44-55$.

Van Maanen, J. (1997). New maths may profit from old methods. For the Learning of Mathematics, 17(2), 39 - 46.

Wilson, P.S., \& Chauvot, J. B. (2000). Who? How? What? A Strategy for Using History to Teach Mathematics. Mathematics Teacher, 93(8), 642-645.

Yevdokimov, O. (2006). Using Materials from the History of Mathematics in Discovery-based Learning, http://eprints.usq.edu.au/3353/1/Yevdokimov_2004-6_ICME10.pdf. (accessed May 2009)

Yin, R. K. (2009). Case study research: Design and methods. Thousand Oaks, CA: SAGE Publications. 